\title{
The Inhibition of Hsp27 Chaperone Affects the Level of p53 Protein in Tumor Cells
}

\author{
E. V. Kaigorodova ${ }^{1,2}$, L. S. Litvinova ${ }^{3}$, E. V. Konovalova ${ }^{1}$, M. V. Klimova ${ }^{2}$, L. A. Tashireva ${ }^{1,2}$, \\ O. L. Nosareva ${ }^{1} \&$ V. V. Novitskiy ${ }^{1}$ \\ ${ }^{1}$ Siberian State Medical University, Tomsk, Russian Federation \\ ${ }^{2}$ Cancer Research Institute of Siberian Branch of the Russian Academy of Medical Sciences, Tomsk, Russian \\ Federation \\ ${ }^{3}$ Immanuel Kant Baltic Federal University, Kaliningrad, Russian Federation \\ Correspondence: E. V. Kaigorodova, Cancer Research Institute of Siberian Branch of the Russian Academy of \\ Medical Sciences, 5 Kooperativny Street, Tomsk 634050, Russian Federation. Tel: 7-382-241-8041. E-mail: \\ zlobinae@mail.ru
}

Received: January 30, 2013 Accepted: March 21, 2013 Online Published: April 23, 2013

doi:10.5539/ijb.v5n3p13 URL: http://dx.doi.org/10.5539/ijb.v5n3p13

\begin{abstract}
The characteristics of $\mathrm{p} 53$ protein content in Jurkat and THP-1 tumor cell line, and mononuclear leukocytes were evaluated from in vitro studies with selective inhibition of the chaperone Hsp27. For the inhibition of Hsp27 KRIBB3 ((5-(5-ethyl-2-hydroxy-4-methoxyphenyl)-4-(4-methoxyphenyl)-isoxasole) was used. The p53 protein concentration was determined by Western blot analysis. The apoptoticly transformed cells with selective inhibitor Hsp27 were assessed by in vitro fluorescence microscopy using FITC-labeled annexin V and propidium iodide. The present study showed that the in vitro inhibition of the chaperone Hsp27 leads to an increase in p53 concentration in tumor cells and a growth of the amount of apoptotic cells in modified Jurkat and THP-1 cultures but revealed no such effects in the mononuclear leukocytes culture. Thus, Hsp27 appeared to play an important regulatory role in the activation of $\mathrm{p} 53$ protein of tumor cells.
\end{abstract}

Keywords: p53 protein, molecular chaperone Hsp27, tumor cells, apoptosis

\section{Introduction}

It is known that a cell incorporates different mechanisms that regulate the processes of survival and death. The key transcription factor involved in the implementation of apoptosis is p53. This protein is activated in response to various forms of cellular stress and is essential for control of anti-proliferative processes. P53 can be induced by DNA damage, hypoxia, or aberrant expression of oncogenes. This protein regulates DNA reparation, cellular senescence, and apoptosis (Levine, Hu, \& Feng, 2006; Lin et al., 2004). Dysfunctions of p53 are accompanied by defects of the protection, genetic instability, cell immortality, which allows the damaged cells to survive and evolve (Beroud \& Soussi, 2003). Taking these facts into account, it ts evident that p53 is the most frequently inactivated suppressor gene of carcinogenesis. p53 in mutated or deactivated form is detected in more than $50 \%$ of human tumors (Kern et al., 1992; Milner, Medcalf, \& Cook, 1991). A number of authors have shown in vivo that a mutant p53 specifically interacts with the molecular chaperone Hsp90 (Heat shock protein-Hsp) (Wang \& Chen, 2003; Smith, Whitesell, \& Katsanis, 1998; Blagosklonny, Toretsky, Bohen, \& Neckers, 1996). However, the molecular interconnections of heat shock protein Hsp27 and p53 remain unknown. Hence, in order to investigate the influence of Hsp27 on the general concentration of the transcription factor p53 in hematological cells and mononuclear leukocytes, obtained from healthy donors, the in vitro specific inhibition with KRIBB-3 was used.

\section{Material and Methods}

\subsection{Material of Research}

The materials used in this study are Jurkat tumor cell lines (T-lymphoblastic human leukemia), THP-1 (monocytic leukemia), obtained from Russian Cell Cultures Collection of the Institute of Cytology of the Russian Academy of Sciences (St. Petersburg), and mononuclear leukocytes isolated from relatively healthy donor blood (donors: 11 men and 16 women, aged 18-45). 
Mononuclear leukocytes (MNL) were isolated under sterile conditions from venous heparin-treated blood by centrifugation with Ficoll-Paque density gradient $\left(\rho=1.077 \mathrm{~g} / \mathrm{cm}^{3}\right.$; «Pharmacia», Sweden) with the ratio 1:2.

The main criteria for participant selection were as follows: absence of infectious diseases, exacerbation of chronic somatic diseases and cancer, mental disorders, alcohol and drug abuse in medical background; age from 18 to 50 years, and informed consent of thee participant.

\subsection{Cultivation of Cells}

Jurkat, THP-1 and MNL cells were cultured in suspension in complete nutrient medium with the following composition: 90\% RPMI-1640 («Vector-Best», Russia), 10\% FCS («Invitrogen», USA) inactivated at $56^{\circ} \mathrm{C}$ for 30 $\min , 0.3 \mathrm{mg} / \mathrm{ml} \mathrm{L}$-glutamine («Vector-Best», Russia), $100 \mu \mathrm{g} / \mathrm{ml}$ gentamicin (INS, USA) at $37^{\circ} \mathrm{C}$ and $5 \% \mathrm{CO}_{2}$ atmosphere. The cells were maintained in the logarithmic growth phase and were subcultured in 3 days. The Hsp27 in the cells was inhibited by adding KRIBB3 (5-(5-ethyl-2-hydroxy -4-methoxyphenyl)-4-(4-methoxyphenyl)-isoxasole) («Sigma-Aldrich», USA) into culture medium.

In order to estimate the Hsp27 apoptotic inhibitor dose, Jurkat tumor cell line $\left(2 \times 10^{6}\right.$ per $\left.1 \mathrm{ml}\right)$ was incubated for 18 hours in culture medium with KRIBB3 final concentrations of $0.1,1,5$, and $10 \mu \mathrm{M}$. Apoptotic and necrotic cells were counted by the method of fluorescence microscopy. The maximum amount of apoptotic cells with corresponding minimum of necrosis ones was registered at $0.1 \mu \mathrm{M}$ of KRIBB3, which was chosen as inhibitor concentration for the further study.

\subsection{Evaluation of Apoptic Cells}

The apoptosis was evaluated by means of fluorescent microscopy on Axiostar plus microscope («Carl Zeiss», Germany) using FITC-labeled annexin V and propidium iodide («PI»; «Abcam», Great Britain). The method is based on specific ability of FITC-labeled annexin V to bind to phosphatidyl serine and PI and to intercalate with DNA molecule. The number of FITC+/PI- and FITC+/PI+-labeled lymphocytes were counted for 200-300 cells and then expressed in percentage.

\subsection{Western Blotting Analysis Based Determination of 533 Concentration}

The cells lysate proteins were separated by electrophoresis under the following conditions: $10 \mathrm{~V} / \mathrm{cm}$ electric field, $5 \%$ and $10 \%$ polyacrylamide gel SDS-PAGE, $14.3-220.0 \mathrm{kDa}$ protein molecular weight markers («Fermentas», EU). Proteins were transferred to the nitrocellulose membranes («Bio-Rad», USA). Then, membranes were incubated sequentially in $0.05 \%$ TTBS, $\mathrm{pH} 7.4(20 \mathrm{mM}$ Tris- $\mathrm{HCl}, 150 \mathrm{mM} \mathrm{NaCl}$ and $0.05 \%$ Tween-20) with $5 \%$ fat free dry milk containing primaries with monoclonal antibodies to p53 («Biosource», USA) and then with peroxidase-labeled secondary antibodies («Biosource», Belgium). The results were recorded on Kodak X-ray film (USA) with Novex chemiluminescent substrate («Invitrogen», USA). The conclusion about the content of the target antigen in cell was based on the signal ratio from the target protein label and the glyceraldehyde-3-phosphate dehydrogenase enzyme, measured with the software TotalLab (G3PDH) («Chemicon», USA). The results were expressed in conventional units.

\subsection{Statistical Analysis}

The data were processed by statistical methods using SPSS 13.0 software. The normality of distribution was verified by the Shapiro-Wilk test. The validity of differences was confirmed by the nonparametric Mann-Whitney test (for samples with abnormal distribution) and the Student two-sample test (for samples with normal distribution). The results are presented as a median (Me) and upper and lower quartiles (Q1-Q3). The differences are considered significant at $\mathrm{p}<0.05$.

\section{Results}

The present study of the total content of p53 transcription factor in lysates of Jurkat and THP-1 tumor cell lines has shown a significantly higher concentration of this parameter in tumor-transformed cells than in mononuclear leukocytes of relatively healthy donors (Figure 1).

This can be explained by the fact that a wild-type p53 is a labile protein with high volatility. It is quickly destroyed via proteolysis and ubiquitin-proteasome pathway, which leads to the low concentrations of p53 in cells. Alongside this, mutated p53 is less dependent on proteolysis or ubiquitination and, therefore, is accumulated in the cells (Beroud \& Soussi, 2003). A higher concentration of p53 in tumor cells can also be explained by the action of heat shock proteins, which are highly expressed in ontogenesis, perform the chaperone functions, stabilize and protect the mutant form of the transcription factor p53 from degradation. Previously, it was shown that the expression level of mRNA Hsp27 is 4 times higher in Jurkat and THP-1tumor cell lines than in mononuclear leukocytes obtained from healthy donors (Kaigorodova et al., 2012; Kaigorodova, 2011). 
In vitro study of the general concentration of $\mathrm{p} 53$ by Western blotting with inhibition of Hsp27 in hematological and normal blood cells has shown a significant increase of this parameter in Jurkat and THP-1tumor cell lines (Figure 1).

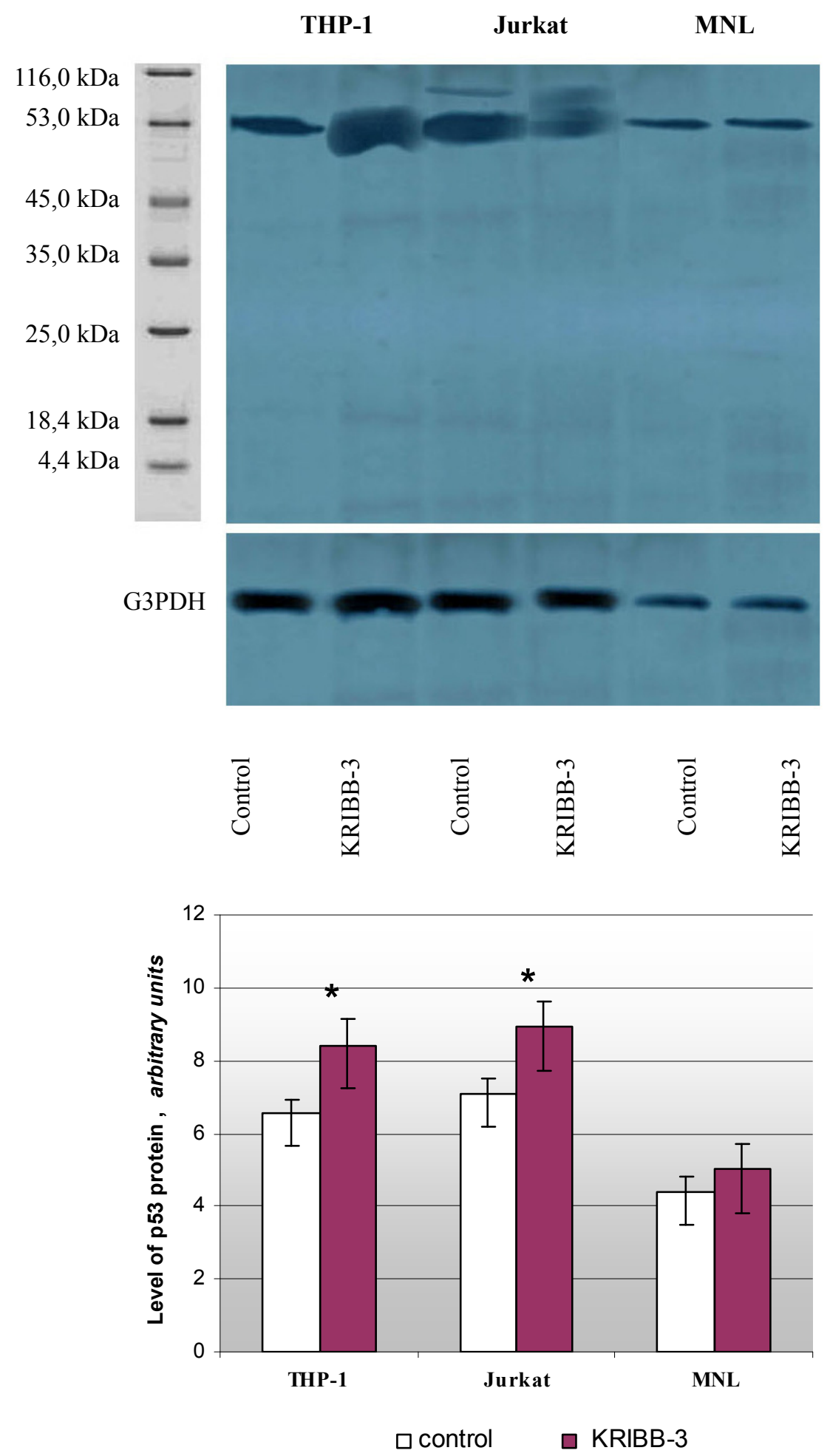

Figure 1. The concentration of p53 protein in Jurkat and THP-1 tumor cell lines and mononuclear leukocytes (MNL) under the effect of inhibitor of Hsp27 chaperone in vitro (according to Western blotting data)

Note: GAPDH - glyceraldehyde 3-phosphate dehydrogenase, KRIBB-3 - selective inhibitor Hsp27; * - certainty factor of differences in comparison with intact cells of the correspondent line with $\mathrm{p}<0.05$. 
It was shown that blocking of HSF-1 (HSF1 - heat shock factor 1) and a decrease in the intracellular level of Hsp27 is a trigger for accumulation of transcriptionally active mutant p53 (Kanagasabai, Krishnamurthy, Druhan, \& Ilangovan, 2011). The results obtained indicate that Hsp27 chaperone regulates the transcriptional activity of p53. There is evidence in favor of this fact in the relevant literature which shows that Hsp27 reduce the doxorubicin-induced apoptosis of fibroblasts and cardiomyocytes, lowering the transcriptional activity of p53 and increasing the activity of p21 (Venkatakrishnan et al., 2008).

It should be emphasised that a sharp increase in the number of apoptotically modified cells was noted under the inhibition of Hsp27 in Jurkat and THP-1tumor cell lines (Kaigorodova, Ryazantseva, Novitsky, Maroshkina, \& Belkina, 2012; Kaigorodova, 2011). Therefore, adding KRIBB3 results in a significant increase of the number of apoptotically altered cells in Jurkat and THP-1tumor culture lines $(p<0,05)$ in contrast to the culture of mononuclear leukocytes obtained from healthy donors $(\mathrm{p}<0,05)$. (Figures 2 and 3 ).

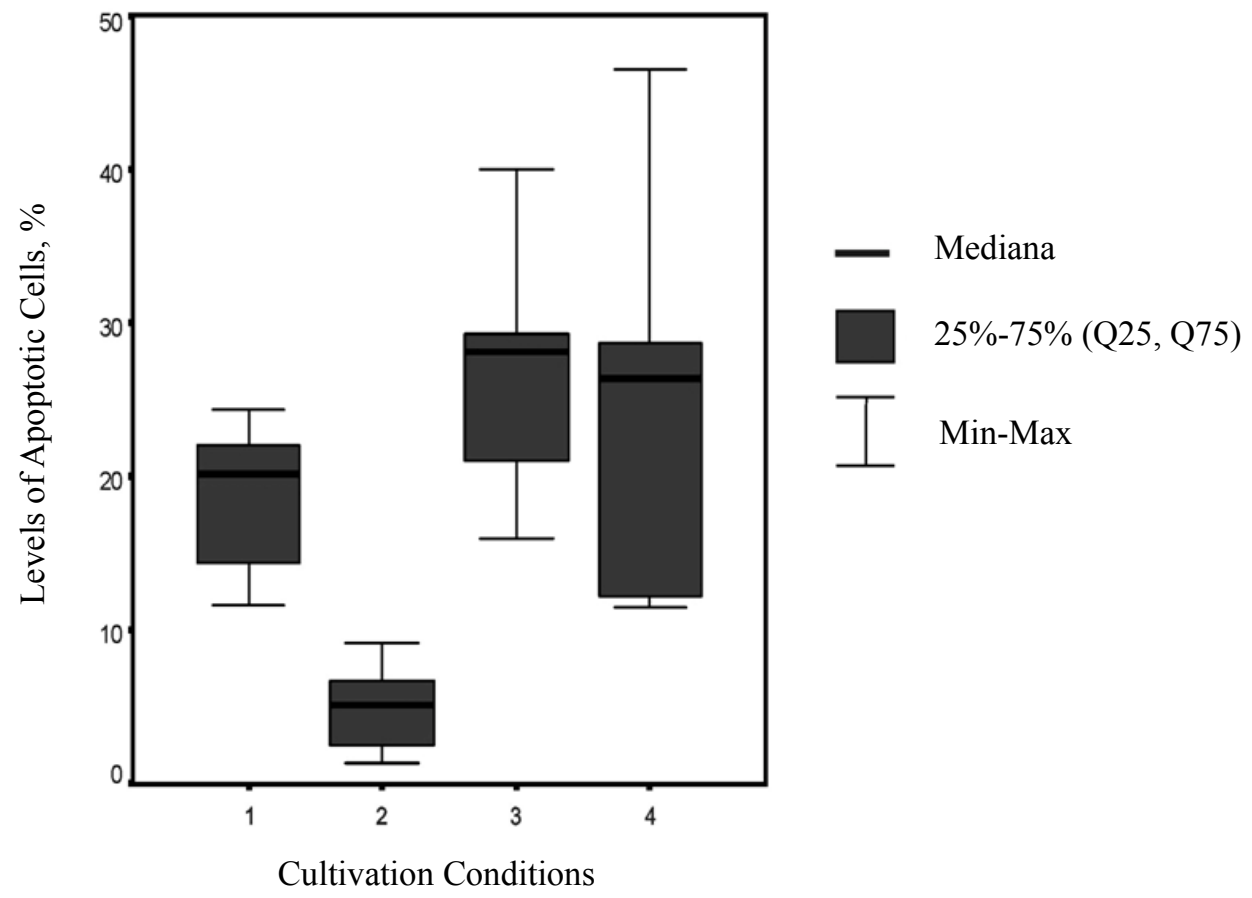

Figure 2. Levels of apoptotic cells under the effects of heat shock protein Hsp27 inhibitor (KRIBB-3) in vitro

1 - intact mononuclear leukocytes obtained from healthy donors,

2 - culture intact tumor cell line Jurkat;

3 - inhibition of Hsp27 (Jurkat cultivation of cells line with $0.1 \mathrm{mM} \mathrm{KRIBB3);}$

4 - inhibition of Hsp27 (cultivation of mononuclear leukocytes with $0.1 \mathrm{mM} \mathrm{KRIBB3}$ ). 

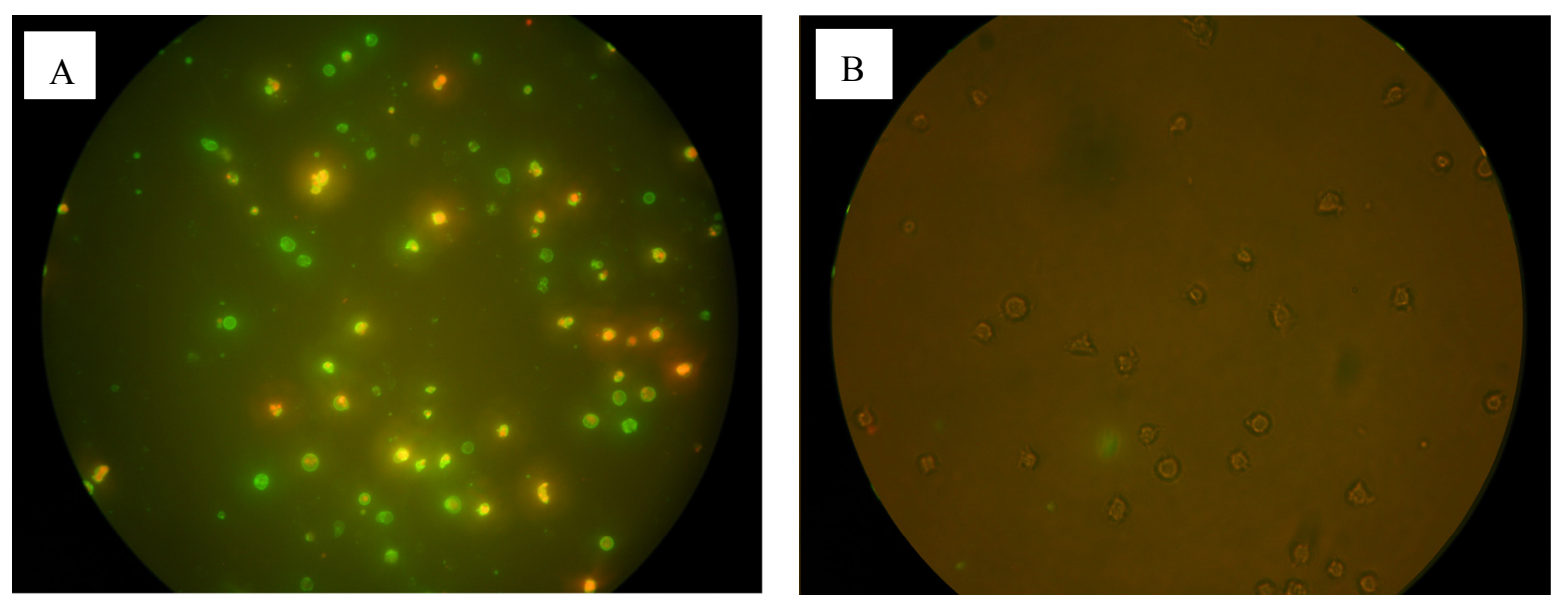

Figure 3. Fluorescent microscopy of annexin V-positive THP-1 cells, $\times 400$

(A) THP-1 cells after addition of $0.1 \mu \mathrm{M}$ KRIBB3; (B) intact THP-1 cells (control)

\section{Discussion}

The study of molecular chaperones and their regulatory mechanisms is an important task of medicine, since it could find specific ways for tumor cells avoiding apoptosis by Hsps and could be used as the basis for targeted therapy of malignant diseases.

It is known that a key transcription factor involved in the implementation of apoptosis is $\mathrm{p} 53$. It is also determined that in more than $50 \%$ of human cancers cases the protein is either in mutated or deactivated form. In such a case, in many cancer cells, one may observe an increased expression of the protein Hsp27 which performs a variety of chaperone functions (folding and refolding of proteins that support the functional activity of intracellular proteins and elimination of damaged protein forms, providing the transport of proteins across cell membranes, providing the association-dissociation processes of intracellular supramolecular complexes protecting proteins from aggregation) (Smith, Whitesell, \& Katsanis, 1998; Nahleh, Tfayli, Najm, El Sayed, \& Nahle, 2012).

The molecular mechanisms regulating cell apoptosis by transcription factor $\mathrm{p} 53$ are various. Thus, $\mathrm{p} 53$ controls the expression of proteins of the Bcl-2 family which perform the apoptotic function, transactivates the gene which encodes Apaf-1, and therefore participates in the implementation of the mitochondrial pathway apoptosis launch (Morgunkova, 2005; Joza et al., 2001). The dysregulation of a programmed cell death under the influence of a selective inhibitor of the molecular chaperone Hsp27, which was registered in vitro in the present study, can be reasonably explained in the context of p53 activation. In particular, the reduction of transmembrane mitochondrial potential can occur as the result of translocation of $\mathrm{p} 53$ towards mitochondria, where it binds antiapoptotic proteins (Bcl-2, Bcl-XL), thus inducing the outgo of the cytochrome c (Prives \& Hall, 1999). We showed earlier that the effect of a selective inhibitor Hsp27 in vitro on Jurkat and THP-1 tumor cell lines involve changing of proapoptotic (Bax and Bad) and anti-apoptotic (Bcl-2) proteins ratio in favor of the former ones, and also lowering the level of mitochondrial transmembrane potential (Kaigorodova, Ryazantseva, Novitsky, Maroshkina, \& Belkina, 2012; Ryazantseva, Kaigorodova, Maroshkina, Belkina, \& Novitsky, 2012; Kaigorodova, 2011). We assume that the chaperone Hsp27 is a molecular target for the targeted impact on the programmed death of tumor cells of T-lymphoblastic leukemia and monocytic leukemia.

\section{Conclusion}

Thus, the results obtained in the study evidentiate the fact of an increase in the intracellular level of p53 in blocking of Hsp27 in vitro, which correspond to the previously obtained and literature data, and indicate an important regulatory role of $\mathrm{Hsp} 27$ chaperones in activation of p53 tumor cells.

In our view, the molecular chaperone Hsp27 is essential for stability and regulation of transcriptional activity of p53 and represent an additional control level of this transcription factor.

\section{Acknowledgements}

The study was carried out with financial support of RF Ministry of Education and Science within the framework of Federal Target Program «Research and Pedagogical Staff of Innovation Russia for 2009-2013» SC.14.A18.21.0174, № 16.512.11.2282, and aslo within the framework of the Council for Grants of the President 
of the Russian Federation for the state support of young philosophy doctors and leading scientific schools, agreements of SC №16.120.11.480-MK, №16.120.11.614-HШ.

\section{References}

Beroud, C., \& Soussi, T. (2003). The UMD-p53 database: new mutations and analysis tools. Hum Mutat, 21(3), 176-181. http://dx.doi.org/10.1002/humu.10187

Blagosklonny, M. V., Toretsky, J., Bohen, S., \& Neckers, L. (1996). Mutant conformation of p53 translated in vitro or in vivo requires functional HSP90. Proc. Natl. Acad. Sci. USA, 93(16), 8379-8383. http://dx.doi.org/10.1073/pnas.93.16.8379

Joza, N., Susin, S. A., Daugas, E., Stanford, W. L., Cho, S. K., Li, C. Y., ... Penninger, J. M. (2001). Essential role of the mitochondrial apoptosis-inducing factor in programmed cell death. Nature, 410(6828), 549-554. http://dx.doi.org/10.1038/35069004

Kaigorodova, E. V. (2011). Molecular mechanisms of regulatory action of heat shock protein $27 \mathrm{kDa}$ in the apoptosis of tumor cells. Bulletin of Siberian Medicine, 10(4), 71-76.

Kaigorodova, E. V., Maroshkina, A. N., Tashireva, L. A., Cherkasova, E. A., Konovalova, E. V., Ryazantseva, N. V., \& Novitskii, V. V. (2012). Feature of gene expression and content of phosphorylated form of heat shock protein $27 \mathrm{kDa}$ in tumor and normal blood cells. Siberian Oncological Journal Appendix, 1, 75-76.

Kaigorodova, E. V., Ryazantseva, N. V., Novitskii, V. V., Maroshkina, A. N., \& Belkina, M. V. (2012) Effects of HSP27 Chaperone on THP-1 Tumor Cell Apoptosis. Bulletin of Experimental Biology and Medicine. 154(1), 77-79.

Kanagasabai, R., Krishnamurthy, K., Druhan, L. J., \& Ilangovan, G. (2011). Forced expression of heat shock protein 27 (Hsp27) reverses P-glycoprotein (ABCB1)-mediated drug efflux and MDR1 gene expression in Adriamycin-resistant human breast cancer cells. J. Biol. Chem., 286(38), 33289-33300. http://dx.doi.org/10.1074/jbc.M111.249102

Kern, S. E., Pietenpol, J. A., Thiagalingam, S., Seymour, A., Kinzler, K. W., \& Vogelstein, B. (1992). Oncogenic forms of p53 inhibit p53-regulated gene expression. Science, 256(5058), 827-830. http://dx.doi.org/10.1126/science.1589764

Levine, A. J., Hu W., \& Feng, Z. (2006). The P53 pathway: what questions remain to be explored? Cell Death and Diff., 48, 456-462.

Lin, M. T., Chang, C. C., Chen, S. T., Chang, H. L., Su, J. L., Chau, Y. P., \& Kuo, M. L. (2004). Cyr61 expression confers resistance to apoptosis in breast cancer MCF-7 cells by a mechanism of NF-kappaB-dependent XIAP up-regulation. J. Biol. Chem., 279(23), 24015-24023. http://dx.doi.org/10.1074/jbc.M402305200

Milner, J., Medcalf, E. A., \& Cook, A. C. (1991). Tumor suppressor p53: analysis of wild-type and mutant p53 complexes. Mol. Cell. Biol, 11(1), 12-19.

Morgunkova, A. A. (2005). p53 gene family: control of cell proliferation and organism development program. Biochemistry, 70(9), 1157-1176.

Nahleh, Z., Tfayli, A., Najm, A., El Sayed, A., \& Nahle, Z. (2012) Heat shock proteins in cancer: targeting the 'chaperones'. J. Future Med Chem., 4(7), 927-35.

Prives, C., \& Hall, P. A. (1999). The p53 pathway. J. Path, 187, 112-126. http://dx.doi.org/10.1002/(SICI)1096-9896(199901)187:1<112::AID-PATH250>3.0.CO;2-3

Ryazantseva, N. V., Kaigorodova, E. V., Maroshkina, A. N., Belkina, M. V., \& Novitskii, V. V. (2012). Apoptosis-modulating effects of heat shock proteins: effect of Hsp27 chaperone on proteins of Bcl-2 family in Jurkat tumor cell line. Issues of Oncology, 58(4), 541-544.

Smith, D. F., Whitesell, L., \& Katsanis, E. (1998). Molecular chaperones: biology and prospects for pharmacological intervention. Pharm. Rev., 50(4), 493-513.

Venkatakrishnan, C. D., Dunsmore, K., Wong, H., Roy, S., Sen, C. K., Wani, A., ... Ilangovan, G. (2008). Hsp27 regulates p53 transcriptional activity in doxorubicin-treated fibroblasts and cardiac H9c2 cells: p21 upregulation and G2/M phase cell cycle arrest. Am. J. Physiol Heart Circ Physiol, 294(4), 1736-1744. http://dx.doi.org/10.1152/ajpheart.91507.2007

Wang, C., \& Chen, J. (2003). Phosphorylation and Hsp90 binding mediate heat shock stabilization of p53. J. Biol. Chem., 278(3), 2066-2071. http://dx.doi.org/10.1074/jbc.M206697200 